\title{
Predictive epidemiology for SARS-CoV-2 pandemic in Iraq
}

Sir,

Since the initial reports of the Wuhan outbreak, the severe acute respiratory syndrome coronavirus 2 (SARS-CoV-2) pandemic has been spreading around the world at an alarmingly exponential rate. ${ }^{1}$ As of the 29 of September 2020, the number of confirmed infections exceeded 33,578,543 worldwide, and 353,566 cases in Iraq. ${ }^{2}$ Complications related to the illness claimed the lives of over 1,006,955 globally, and 9,502 individuals in Iraq. ${ }^{2}$ SARS-CoV-2 allocated with to nations from the developed and the developing world as well, including the United States, India, Brazil, Russia, Columbia, Peru, Spain, Mexico, Argentina, South Africa, France, Chile, Iran, UK, Bangladesh, Iraq, Saudi Arabia, Turkey, Italy, and Pakistan. ${ }^{2}$ As a top priority for the global health agenda, researchers are working to develop effective vaccines in several nations of the world, including China, Russia, the United Arab Emirates, the United Kingdom, and the United States. ${ }^{3}$ Coronaviruses represent a family of enveloped positive-strand RNA viruses that can infect species of vertebrates, including humans. ${ }^{1,2}$ Coronaviruses include thirty-nine species that belong to the family Coronaviridae, suborder Cornidovirineae, order Nidovirales, and the realm of Riboviria. ${ }^{1}$ The mutation rates of the genome of RNA viruses occurs faster than those of DNA viruses, which indicates a more efficient adaptation process for survival in Coronaviruses..$^{1,2}$ During the past two decades, Coronaviruses caused two epidemics, the severe acute respiratory syndrome (SARS) and the Middle East respiratory syndrome (MERS) in 2002-2003 and 2012, respectively. ${ }^{1,4}$

Our study is the first in the literature, in connection with the Iraqi situation on SARS-CoV-2 pandemic, to implement non-Bayesian predictive analytics. Our primary objective is to provide high-order polynomial predictive models that best explain the total cases, daily new cases, active cases, total deaths, and the daily deaths caused by SARS-CoV-2 in Iraq. Our secondary objective is to examine the bivariate correlations among the same parameters. Thereby, we are highlighting the noteworthiness of modalities of artificial intelligence, including predictive analytics and machine learning, to the Iraqi authorities, specifically the Iraqi Ministry of Health, through which Iraq can deploy

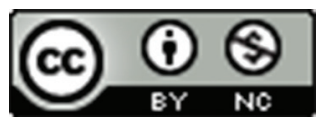

This work is licensed under a Creative Commons Attribution-NonCommercial 4.0 International License.

precautionary and preventive measures in facing the pandemic. ${ }^{5-8}$ The authors carried out the work described in this manuscript following the Code of Ethics of the World Medical Association [Declaration of Helsinki] on medical research involving human subjects, EU Directive (210/63/EU), the uniform requirements for manuscripts submitted to biomedical journals and the ethical principles defined in the Farmington Consensus of 1997.

\section{MACRO-EPIDEMIOLOGY OF SARS-COV-2 PANDEMIC IN IRAQ}

Several renowned websites are providing a quasi-real-time stream of data on coronavirus disease 2019 (COVID-19) worldwide. These websites are not limited to open access databases available via the World Health Organization, COVID-19 Tracker of Microsoft's Bing search engine, the Worldometer website, and many others. ${ }^{2}$ We used the Worldometer website because its data “... is also trusted and used by the UK Government, Johns Hopkins CSSE, the Government of Thailand, the Government of Pakistan, Financial Times, The New York Times, Business Insider, BBC, and many others." Besides, their data have been "requested by, and provided to Oxford University Press, Wiley, Pearson, CERN, World Wide Web Consortium (W3C),..." ${ }^{2}$ Using a Python script and a web-scraping tool, we retrieved data for the period from the 24 of 
February 2020 (date of patient zero in Iraq) to the 25 of September $2020 .{ }^{9}$

Using IBM SPSS version 24 and Microsoft Excel 2016, we succeeded in creating five predictive models, and each has a strong correlation coefficient (Table 1, Figure 1, and Figure 2). The strongest three models were for predicting the total cases of SARS-CoV-2 $\left(y=4 \mathrm{E}-08 \mathrm{x}^{6}-3 \mathrm{E}-05 \mathrm{x}^{5}\right.$
$+0.0063 \mathrm{x}^{4}-0.6291 \mathrm{x}^{3}+26.013 \mathrm{x}^{2}-365.41 \mathrm{x}+1079.1$ $\mathrm{R}^{2}=0.9997$, Correlation Coefficient $\left.=0.9999\right)$, the total deaths $\left(y=5 E-09 x^{6}-3 E-06 x^{5}+0.0007 x^{4}-0.0756 x^{3}\right.$ $+3.3674 \mathrm{x}^{2}-55.82 \mathrm{x}+218.7, \mathrm{R}^{2}=0.9986$, Correlation Coefficient $=0.9993)$, and the active cases $\left(y=-5 E-09 x^{6}\right.$ $+4 \mathrm{E}-06 \mathrm{x}^{5}-0.0015 \mathrm{x}^{4}+0.2414 \mathrm{x}^{3}-16.692 \mathrm{x}^{2}+421.28 \mathrm{x}$ - 2314.2, $R^{2}=0.9904$, Correlation Coefficient=0.9952). The least strong models were for predicting the daily

\section{Table 1: Polynomial Predictive Models of SARS-CoV-2 Pandemic in Iraq}

\begin{tabular}{|c|c|c|c|c|c|}
\hline Parameter* & Equation of the Predictive Model ${ }^{* *}$ & $\begin{array}{l}\text { Order of Polynomial } \\
\text { Function }\end{array}$ & $\mathbf{R}^{2}$ Score & $\begin{array}{l}\text { Correlation } \\
\text { Coefficient }\end{array}$ & $\begin{array}{c}\text { Effect } \\
\text { Size }\end{array}$ \\
\hline Total cases & $\begin{array}{l}y=4 E-08 x^{6}-3 E-05 x^{5}+0.0063 x^{4}-0.6291 x^{3}+26.013 x^{2} \\
-365.41 x+1079.1\end{array}$ & $6^{\text {th }}$ & 0.9997 & 0.9999 & Strong \\
\hline Total deaths & $\begin{array}{l}y=5 E-09 x^{6}-3 E-06 x^{5}+0.0007 x^{4}-0.0756 x^{3}+3.3674 x^{2} \\
-55.82 x+218.7\end{array}$ & $6^{\text {th }}$ & 0.9986 & 0.9993 & Strong \\
\hline Active cases & $\begin{array}{l}y=-5 E-09 x^{6}+4 E-06 x^{5}-0.0015 x^{4}+0.2414 x^{3}-16.692 x^{2} \\
+421.28 x-2314.2\end{array}$ & $6^{\text {th }}$ & 0.9904 & 0.9952 & Strong \\
\hline Daily new cases & $\begin{array}{l}y=-1 E-09 x^{6}+7 E-07 x^{5}-0.0002 x^{4}+0.0335 x^{3}-2.0904 x^{2} \\
+48.421 x-245.61\end{array}$ & $6^{\text {th }}$ & 0.9663 & 0.9830 & Strong \\
\hline Daily deaths & $\begin{array}{l}y=-4 E-11 x^{6}+4 E-08 x^{5}-2 E-05 x^{4}+0.0024 x^{3}-0.1545 x^{2} \\
+3.6878 x-19.294\end{array}$ & $6^{\text {th }}$ & 0.8869 & 0.9418 & Strong \\
\hline
\end{tabular}

*Date: 24.02 .2020 to 25.09 .2020

$* * y=$ predicted number of cases/death, $x=$ time.



Figure 1: Daily New Cases of SARS-CoV-2 [Date: 24.02.2020 to 25.09.2020]

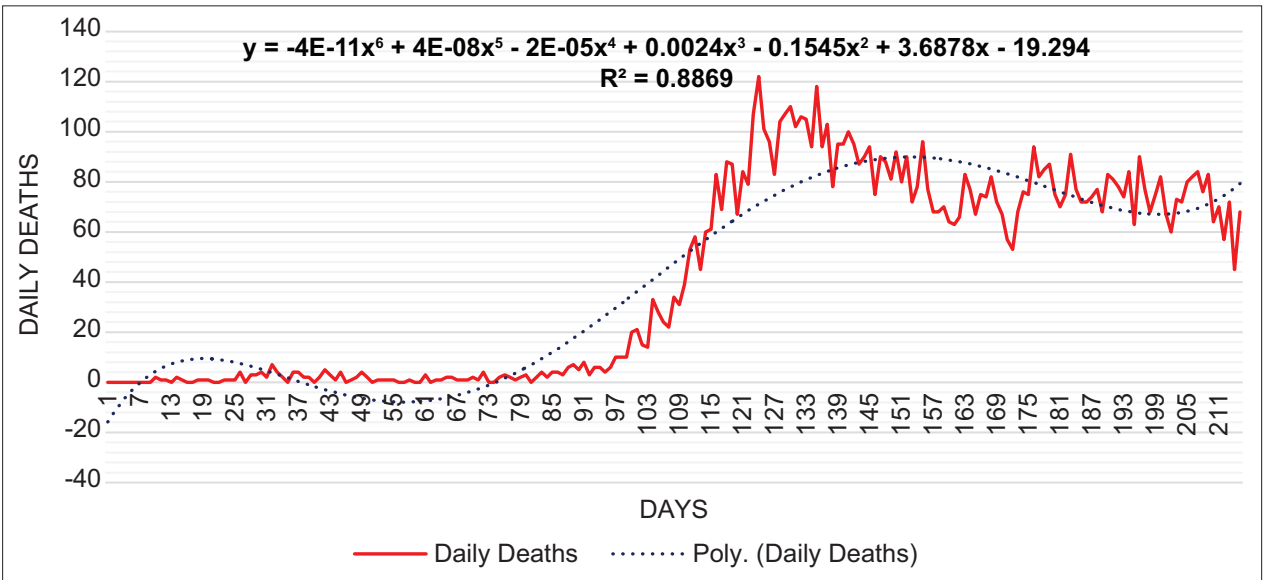

Figure 2: Daily Deaths of SARS-CoV-2 [Date: 24.02 .2020 to 25.09.2020] 


\begin{tabular}{|c|c|c|c|c|c|c|}
\hline & & Total cases & Daily new cases & Active cases & Total deaths & Daily deaths \\
\hline \multirow[t]{3}{*}{ Total cases } & Kendall's tau-b & 1.000 & $.876^{* *}$ & $.959^{* *}$ & $.999^{* *}$ & $.581^{* *}$ \\
\hline & Sig. (2-tailed) & & .000 & .000 & .000 & .000 \\
\hline & $\mathrm{N}$ & 215 & 215 & 215 & 215 & 215 \\
\hline \multirow[t]{3}{*}{ Daily new cases } & Kendall's tau-b & $.876^{\star *}$ & 1.000 & $.887^{\star \star *}$ & $.876^{\star \star}$ & $.617^{\star *}$ \\
\hline & Sig. (2-tailed) & .000 & & .000 & .000 & .000 \\
\hline & $\mathrm{N}$ & 215 & 215 & 215 & 215 & 215 \\
\hline \multirow[t]{3}{*}{ Active cases } & Kendall's tau-b & $.959^{* *}$ & $.887^{* *}$ & 1.000 & $.958^{\star *}$ & $.595^{\star *}$ \\
\hline & Sig. (2-tailed) & .000 & .000 & . & .000 & .000 \\
\hline & $\mathrm{N}$ & 215 & 215 & 215 & 215 & 215 \\
\hline \multirow[t]{3}{*}{ Total deaths } & Kendall's tau-b & $.999^{* *}$ & $.876^{\star *}$ & $.958^{\star *}$ & 1.000 & $.582^{* \star}$ \\
\hline & Sig. (2-tailed) & .000 & .000 & .000 & & .000 \\
\hline & $\mathrm{N}$ & 215 & 215 & 215 & 215 & 215 \\
\hline \multirow{3}{*}{ Daily deaths } & Kendall's tau-b & $.581^{* \star}$ & $.617^{\star \star}$ & $.595^{\star \star}$ & $.582^{* \star}$ & 1.000 \\
\hline & Sig. (2-tailed) & .000 & .000 & .000 & .000 & \\
\hline & $\mathrm{N}$ & 215 & 215 & 215 & 215 & 215 \\
\hline
\end{tabular}

new cases $\left(y=-1 E-09 x^{6}+7 E-07 x^{5}-0.0002 x^{4}+0.0335 x^{3}\right.$ - 2.0904 $x^{2}+48.421 x-245.61, R^{2}=0.9663$, Correlation Coefficient $=0.9830)$ (Figure 1), and the daily deaths from SARS-CoV-2 $\left(y=-4 \mathrm{E}-11 \mathrm{x}^{6}+4 \mathrm{E}-08 \mathrm{x}^{5}-2 \mathrm{E}-05 \mathrm{x}^{4}+0.0024 \mathrm{x}^{3}\right.$ $-0.1545 x^{2}+3.6878 x-19.294, R^{2}=0.8869$, Correlation Coefficient $=0.9418)($ Figure 2$)$.

According to the Shapiro-Wilk test of normality, all the parameters of interest followed a non-normal distribution, including the total cases of SARS-CoV-2 (test statistic $=0.762, \mathrm{df}=215, \mathrm{p}$-value $<0.001)$, daily new cases $(0.837,215, \mathrm{p}<0.001)$, active cases $(0.809,215$, $\mathrm{p}<0.001)$, total deaths $(0.782,215, \mathrm{p}<0.001)$, and the daily deaths $(0.817,215, \mathrm{p}<0.001)$. Therefore, we conducted a nonparametric correlation, Kendall's tau bivariate correlations. Significant positive correlations existed among all the parameters, most of which had a strong effect size (Table 2). Few correlations had a medium (moderate) effect size, including daily deaths versus total cases (Kendall's tau-b correlation coefficient $=0.581, \mathrm{p}<0.001)$, daily deaths versus daily new cases $(0.617 \mathrm{p}<0.001)$, daily deaths versus active cases $(0.595, \mathrm{p}<0.001)$, and daily deaths versus total deaths $(0.582, \mathrm{p}<0.001)$ (Table 2$)$. Our models were triumphant, but the least, when it comes to predicting the daily new cases and daily deaths from SARS-CoV-2.

\section{CONCLUSION}

We opine that the current study is of prime importance for epidemiology-based decision making by health officials, and it can provide novel information and insights to predict future changes in the SARS-CoV-2 pandemic in developing countries, including countries from the Middle East, that can be conveyed to the Iraqi authorities as well as international authorities for precautionary and preventive measures in facing the pandemic.

\section{AVAILABILITY OF DATA}

Our Data, including raw dataset, are available upon request from the corresponding author.

\section{CONFLICT OF INTEREST}

The authors declare that they have no conflict of interest and that they have self-funded this study.

Key words: Coronaviridae; COVID-19; epidemiology; Iraq; novel coronavirus; predictive analytics; SARS-CoV-2

\section{Ahmed Al-Imam ${ }^{1,2}$, Usama Khalid ${ }^{3}$, Hend Al-Doori ${ }^{4}$}

${ }^{1}$ Department of Anatomy and Cellular Biology, College of Medicine, University of Baghdad, Iraq, ${ }^{2}$ Barts and The London School of Medicine and Dentistry, Queen Mary University of London, the United Kingdom, ${ }^{3}$ Enjaz Limited Liability Company, Baghdad, Iraq, ${ }^{4}$ Al-Betool Teaching Hospital, Diyala Health Directorate, Ministry of Health, Iraq

Address for Correspondence: Dr. Ahmed Al-Imam, Department of Anatomy and Cellular Biology, College of Medicine, University of Baghdad [Iraq]. Mobile No: +964 (0) 771433 8199. E-mail: ahmed.lutfi@uob.edu.iq

\section{REFERENCES}

1. Motyka MA, Al-Imam A and Aljarshawi MHA. SARS-CoV-2 pandemic as an anomie. Social Space/PrzestrzeńSpołeczna. 2020; 20.

2. Worldometer - real time world statistics [Internet]. Worldometer. 2020 [cited 29 September 2020]. Available from: https://www. worldometers.info/

3. Amanat $F$ and Krammer F. SARS-CoV-2 Vaccines: Status Report. Immunity. 2020; 52(4): 583-589. https://doi.org/10.1016/j.immuni.2020.03.007

4. De Wit E, Van Doremalen N, Falzarano D and Munster VJ. SARS and MERS: recent insights into emerging coronaviruses. Nature Reviews Microbiology. 2016; 14: 523-534. 
https://doi.org/10.1038/nrmicro.2016.81

5. Al-Imam A, Motyka MA and Jędrzejko MZ. Conflicting Opinions in Connection with Digital Superintelligence. IAES International Journal of Artificial Intelligence. 2020; 9(2): 336-348. https://doi.org/10.11591/ijai.v9.i2.pp336-348

6. Al-Imam A, Motyka MA, Sahai A and Konuri VK. The "March of Progress": From Cosmic Singularity to Digital Singularity. Current Trends in Information Technology. 2020; 10(1): 1-8.

7. Al-Imam A and Motyka MA. On the Necessity for Paradigm Shift in Psychoactive Substances Research: The Implementation of Machine Learning and Artificial Intelligence. Alcoholism and Drug Addiction/AlkoholizmiNarkomania. 2019; 32(3): 1-6.

https://doi.org/10.5114/ain.2019.91004

8. Al-Imam A and Al-Lami F. Machine Learning for Potent Dermatology Research and Practice. Journal of Dermatology and Dermatologic Surgery. 2020; 24(1): 1-4.

https://doi.org/10.4103/jdds.jdds_54_19

9. Web Scraper - The \#1 web scraping extension [Internet]. Webscraper.io. 2020 [cited 29 September 2020]. Available from: https://www.webscraper.io/

\section{Author's Contribution:}

Ahmed Al-Imam worked on raw data, conducted data analytics, wrote the first draft of the article, and prepared the manuscript for scholarly submission. Usama Khalid collected data from the surface web using a dedicated python script (code) and web-scraping tools. Hend Al-Doori Contributed to writing the first draft.

Work attributed to:

Department of Anatomy and Cellular Biology, College of Medicine, University of Baghdad, Iraq.

Orcid ID:

Dr. Ahmed Al-Imam - (i) https://orcid.org/0000-0003-1846-9424

Source of funding: Nil, Conflict of Interest: None declared. 